\title{
SENSACIONALISMO O SERVICIO PÚBLICO EN LAS INFORMACIONES SOBRE MENORES DESAPARECIDOS
}

\section{Sensationalism or public service in the information on missing children}

\section{Adolfo Carratalá y Dolors Palau-Sampio}

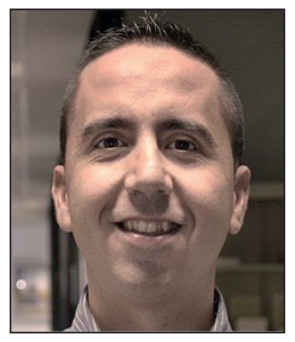

Adolfo Carratalá es doctor en Comunicación por la Universitat de València (UV) con premio extraordinario de doctorado. Profesor de Periodismo en dicha universidad, ha trabajado como profesor asociado en el Grado en Comunicación de la Universidad Internacional de la Rioja (UNIR) y como investigador posdoctoral en la Universidad Rey Juan Carlos (URJC). Su tesis doctoral obtuvo el Premio Lorenzo Gomis de la Sociedad Española de Periodística en 2013.

http://orcid.org/0000-0002-9865-9246

adolfo.carratala@uv.es

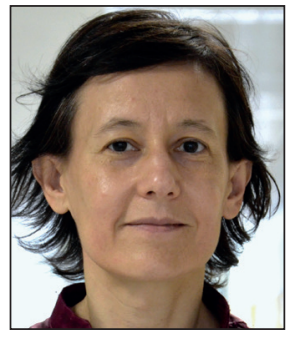

Dolors Palau-Sampio es profesora contratada doctora de Periodismo en la Universitat de València. Licenciada y doctora en Periodismo por la Universitat Autònoma de Barcelona, trabajó como redactora en el periódico Levante-EMV de Valencia. Su investigación se centra en los géneros y estilos periodísticos, la calidad periodística y los cibermedios.

http://orcid.org/0000-0001-9051-0239

dolors.palau@uv.es

Universitat de València, Departamento de Teoría de los Lenguajes y Ciencias de la Comunicación Av. Blasco Ibáñez, 32. 46010 Valencia, España

\section{Resumen}

Las desapariciones de menores colocan a los periodistas ante el desafío de informar sobre un hecho que encierra un elevado interés humano pero que exige rigor y cautela. La acción de los medios puede explotar los componentes emotivos del suceso en busca de audiencia o cooperar con la investigación facilitando la colaboración ciudadana y evitando conjeturas. Este trabajo examina cuáles son las características dominantes en estas noticias a partir del estudio del tratamiento que cuatro diarios españoles (El país, ABC, La vanguardia y El periódico) ofrecieron de los 15 casos recogidos en la web de la asociación SOS Desaparecidos, ocurridos entre 1977 y 2015. El análisis detecta una atención desigual de los medios a las desapariciones y un predominio del enfoque sensacionalista.

\section{Palabras clave}

Periodismo; Cobertura periodística; Sensacionalismo; Servicio público; Ética; Privacidad; Interés humano; Desapariciones; Menores.

\begin{abstract}
Missing children pose to journalists the challenge of reporting on facts that offer high human interest, but this requires rigor and caution. Media coverage can exploit the emotional components of the event in order to increase the audience or it can cooperate with the investigation by facilitating citizen collaboration and avoiding speculation. This paper examines the key features in this kind of news and information for this article is drawn from the study of four Spanish newspapers' (El país, $A B C$, La vanguardia, and El periódico) coverage about the 15 missing cases reported in the SOS Desaparecidos association's website -which all occurred between 1977 and 2015. The analysis detects an unequal amount of media attention paid to the disappearances and a predominantly sensationalist approach.
\end{abstract}

\section{Keywords}

Journalism; Media coverage; Sensationalism; Public service; Ethics; Privacy; Human interest; Disappearances; Children.

Carratalá, Adolfo; Palau-Sampio, Dolors (2017). "Sensacionalismo o servicio público en las informaciones sobre menores desaparecidos". El profesional de la información, v. 26, n. 2, pp. 172-180. 


\section{Cobertura informativa sobre desapariciones de menores}

\subsection{Atractivo periodístico y construcción mediática}

Las desapariciones de personas son un habitual tema de interés para los medios. Como ocurre con el resto de hechos vinculados con el crimen y los sucesos, las desapariciones sin explicación son una ruptura de la estabilidad y, por tanto, emergen como objeto de atención informativa. Son noticias que implican desorden social (Gans, 1979) al dar cuenta de hechos que perturban el sosiego público y pueden suponer violencia contra la vida, especialmente cuando se trata de desapariciones no voluntarias. Estos casos permiten a los medios de comunicación ejercer como instrumentos que deben velar por la compulsión de las normas sociales y señalar toda conducta desviada (Lazarsfeld; Merton, 1985).

Las informaciones sobre desaparecidos cumplen con "valores noticia" (criterios para seleccionar noticias) que son decisivos en la construcción de la agenda mediática, como el conflicto, la negatividad y el drama (Johnson-Cartee, 2005), el suspense (Warren, 1979) y el interés humano (Herbert, 2000). Esta característica, capaz de evocar en la audiencia sentimientos de compasión, pena y admiración (Gans, 1979), es especialmente relevante en la tradición periodística angloamericana y se intensifica cuando la persona desaparecida es menor de edad.

Investigaciones previas han demostrado que las coberturas sobre desapariciones favorecen una percepción desproporcionada de su incidencia real

En Estados Unidos las desapariciones de niños alcanzaron una extraordinaria visibilidad a mediados de los 80 como resultado de una actividad retórica con la que diversos actores, sobre todo progenitores de menores secuestrados, quisieron llevar estos sucesos a la agenda nacional (Best, 1987). La colaboración de los medios de comunicación resultó clave para elevar las desapariciones de menores a la categoría de problema social (Fritz; Altheide, 1987). Sin embargo, su cobertura incorporó distorsiones sistemáticas (Seale, 2003), en especial relacionadas con el alcance real de la amenaza, como suele ocurrir en la construcción de los pánicos morales (Goode; Ben-Yehuda, 1994; Critcher, 2008).

La alusión a la cifra de en torno al millón y medio de menores desaparecidos al año en EUA era frecuente. La mayor parte de los casos se correspondían con adolescentes que se escapaban de casa o con padres que se llevaban consigo a sus hijos durante procesos de separación. Sin embargo, los medios no realizaban esas precisiones y se centraban en abordar dramáticamente episodios de secuestros por parte de desconocidos (Fritz; Altheide, 1987), lo que favoreció una percepción sobre la magnitud del problema alejada de su incidencia real y basada en casos específicos, narrados como situaciones de pánico, incertidumbre y desesperación (Greer; McLaughlin, 2012). Pese a que las estadísticas señalaban que el número de desapariciones a manos de extraños era ínfimo (Staller, 2010), la Administración esta- dounidense impulsó medidas para atajar un problema que activistas y medios habían desproporcionado. La amenaza no era una condición objetiva de la vida de los menores sino fruto de la percepción subjetiva de los adultos (Critcher, 2002). Estudios posteriores han encontrado el mismo desenfoque en medios británicos (Kitzinger; Skidmore, 1995) y australianos (Wilczynski; Sinclair, 1999).

La poderosa imagen simbólica del menor como víctima y la retórica del miedo son dos ingredientes clásicos en la construcción de relatos mediáticos

Las investigaciones sobre el tratamiento mediático de desapariciones han identificado un segundo sesgo sobre las características de la víctima. El "síndrome de la mujer blanca desaparecida" alude a la excesiva cobertura de casos en los que la persona de la que se desconoce el paradero es mujer, blanca, joven, atractiva y de clase media-alta (Stillman, 2007; Liebler, 2010), mientras el resto de episodios se ignoran o se abordan superficialmente. El sexo, la edad, la raza, el nivel socioeconómico y el atractivo de la persona desaparecida son factores condicionantes de la respuesta mediática (Conlin; Davie, 2015). Los mismos criterios determinarían la cobertura de las desapariciones de menores (Brookman, 2005; Greer; McLaughlin, 2012).

\subsection{Precauciones deontológicas y tentaciones sensa- cionalistas}

El tratamiento de los menores en los medios de comunicación debe respetar algunas recomendaciones como la protección de su imagen e identidad (Save the Children; Unicef, 2010) o la no publicación de informaciones que puedan afectar a su reputación (Unió de Periodistes Valencians, 2004), como imágenes siendo violentados o detalles escabrosos y morbosos (Belda-García; Maíllo-Belda; PrietoAmpudia, 2008).

Sin embargo, los niños siempre han sido un elemento preciado en la producción periodística por su capacidad para atraer la atención de la audiencia (Moeller, 2002). Como indica Redondo-García (2013, p. 241):

"las historias que tienen a niños como protagonistas [...] son temas con especial atractivo, gracias a que provocan una reacción sentimental automática".

Los menores aparecen representados como individuos ante los que la sociedad debe responder (Altheide, 2003) y, por tanto, resultan un ingrediente esencial de todo proceso de construcción de pánico moral (Critcher, 2008). El inestimable valor de los niños se convirtió en un argumento clave de la estrategia retórica que buscó hacer de las desapariciones un problema social y muchos testimonios y coberturas informativas se centraron en la sensación de pérdida experimentada por los padres (Best, 1987).

El poder simbólico del menor se intensifica cuando es representado como víctima o victimario (Altheide, 2002) en un discurso donde comparte protagonismo con el miedo, otro tradicional factor determinante del relato mediático que busca atraer el interés de la audiencia a través del en- 
tretenimiento (Glassner, 1999; Altheide, 2003). Cuando la noticia sitúa al niño inocente como víctima de un delito, el mensaje que se ofrece es el de un crimen contra lo sagrado, con todo el poder de atracción emotiva que tal imagen supone (Greer; McLaughlin, 2012).

Por ello los medios se encuentran a menudo en la tensión generada por la responsabilidad de proteger a los menores y la compulsión de situarlos en un lugar central para originar atención (Moeller, 2002). En la cobertura de desapariciones, el difícil equilibrio se ha decantado por el deseo de lograr y mantener audiencias (Fritz; Altheide, 1987), una práctica a la que contribuye la escasez de indicaciones deontológicas sobre cómo actuar en estos casos. Las pocas reflexiones formuladas recuerdan la necesidad de:

- comprobar cualquier anuncio de desaparición que llegue al medio (El país, 1996);

- evitar alarmas generales e informar rápidamente si el desaparecido es un menor (RTVE, 2010);

- privilegiar la identificación del niño frente a su privacidad en una primera fase de cobertura (BBC, 2010);

- mostrar especial sensibilidad con sus parientes, sobre todo en fechas clave como el aniversario del suceso (Bucqueroux; Seymour, 2009).

El claro esquema moral que acompaña los casos de niños desaparecidos a manos de extraños, con una evidente distinción entre los papeles de víctima y villano, facilita que los medios los aborden con estrategias sensacionalistas (Griffin; Miller, 2008). El resultado es un relato dramatizado que acostumbra a centrarse en casos específicos (Best, 1987; Wilczynski; Sinclair, 1999; Kitzinger; Skidmore, 1995; Critcher, 2008) y que emplea profusamente imágenes y enmarcados visuales (Best, 1987; Conlin; Davie, 2015), con el objetivo de que la audiencia se sienta identificada con los protagonistas de la noticia. Un claro ejemplo es el seguimiento informativo de la desaparición de la menor Madeleine McCann en Portugal en mayo de 2007. En este caso, la prensa ofreció una exagerada cobertura de marcado carácter emotivo a través de un espectáculo dramático dominado por la serialidad y la personalización (Luzón; Ferrer, 2008), en una narración de suspense con un elevado componente icónico (Redondo-García, 2013) que sumó, además, un juicio mediático paralelo a los padres de la pequeña. Todo ello hizo del caso un evento global de infoentretenimiento (Greer; McLaughlin, 2012).

Pese a que el tratamiento sensacionalista ha sido más frecuente en la televisión que en la prensa (Fritz; Altheide, 1987) y más propio de los diarios tabloides británicos que de los conocidos diarios de referencia (Wilczynski; Sinclair, 1999; Stillman, 2007), investigaciones recientes señalan que el enfoque impactante de las desapariciones de menores invade también el terreno de la pretendida prensa seria (Redondo-García, 2013).

\section{Los medios como aliados de la investigación}

Durante la cobertura de la desaparición de un menor, la labor de los medios de comunicación se enmarca en una red de interacciones con otros actores clave en el proceso, especialmente los familiares del niño y las fuerzas de seguridad.
Para los primeros, los medios suponen un aliado esencial en el objetivo de movilizar apoyo popular para dar con su allegado (Best, 1987), actuando así como plataformas de quienes abanderan una causa (Critcher, 2008). Por ello, asociaciones creadas para asesorar a familias con personas desaparecidas han elaborado documentos con orientaciones sobre cómo gestionar la relación con los periodistas y optimizar al seguimiento mediático de sus casos (Missing People, 2011; Barrios-Vallejo, 2016; MPAN, 2016).

La interacción entre periodistas y policía parece más complicada dado que ambos colectivos se han mirado tradicionalmente desde la desconfianza y la sospecha (Selke; Bartoszek, 1984). No obstante, ambos se necesitan dado el carácter simbiótico de su relación (Guffey, 1992). Las escasas recomendaciones deontológicas existentes para el tratamiento de desapariciones recuerdan la importancia de que los periodistas inicien el seguimiento informativo "en colaboración con las fuerzas encargadas de la búsqueda" (RTVE, 2010) y de que la decisión de identificar al menor se tome conjuntamente con los padres y los responsables de la investigación (BBC, 2010). Estos son además las principales fuentes con las que los periodistas construyen la cobertura de estos episodios (Kitzinger; Skidmore, 1995; Wilczynski; Sinclair, 1999).

También la policía requiere de los medios para alcanzar diversos objetivos (Innes, 1999), por lo que necesita establecer con ellos una relación de cooperación similar a la que se busca ante fenómenos como el secuestro con rehenes o el terrorismo (Alexander, 1978; Gladis, 1979). Las fuerzas de seguridad cuentan también con indicaciones sobre cómo gestionar su relación con los medios durante la investigación de una desaparición (NPIA, 2010; Findlay; Lowery, 2011). La policía ha buscado directamente la colaboración de los medios en estos episodios con iniciativas como el programa americano de alertas Amber (America's missing broadcast emergency response), que busca difundir cuanto antes por medios audiovisuales la advertencia de que un menor ha desaparecido para intentar recabar pistas de la ciudadanía de manera precoz. No obstante, su eficacia no parece demasiado elevada y actúa más a un nivel de control simbólico (Griffin et al., 2007; Griffin; Miller, 2008).

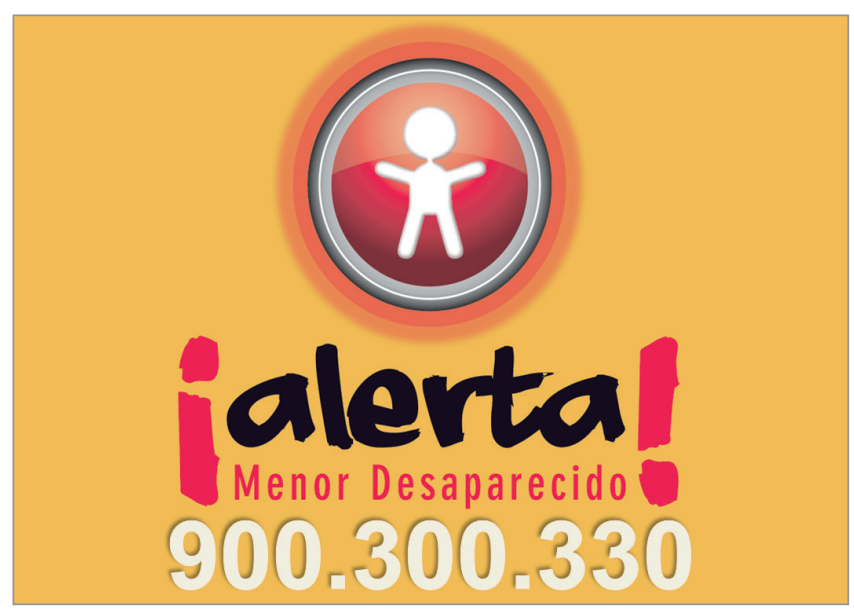

Logo Alerta de menor desaparecido, Ministerio del Interior, España http://www.interior.gob.es/web/servicios-al-ciudadano/colaboracionciudadana 
En España funciona desde 2014 el sistema "Alerta, menor desaparecido", impulsado por el Ministerio del Interior para la emisión de avisos y llamamientos de colaboración ciudadana a través de los medios. Algunos, como RTVE y La vanguardia, además de la FAPE (Federación de Asociaciones de la Prensa de España), firmaron el convenio de colaboración.

Aunque la cobertura de las desapariciones de menores no destaque por incorporar elementos y piezas dedicadas a la prevención (Kitzinger; Skidmore, 1995; Wilczynski; Sinclair, 1999), los ejemplos de colaboración entre medios y policía son una clara muestra de servicio público (Rudin; Ibbotson, 2003) o del llamado periodismo de servicio, en la medida en que se trata de contenidos que pueden resultar útiles en la esfera personal pero también social (Diezhandino-Nieto, 1993).

Son varias las iniciativas ideadas para lograr la colaboración ciudadana y ayudar a la policía en sus investigaciones, como los programas americanos Secret witness, en la prensa local, o Crime stoppers, en televisión (Guffey, 1992), el británico Crimewatch UK, emitido por la BBC (Schlesinger; Tumber, 1993) o el español Quién sabe dónde, que dirigió el periodista Paco Lobatón en TVE entre 1992 y 1998.

Los medios no privilegian la colaboración ciudadana como se desprende de las escasas descripciones físicas y vías de contacto publicadas en las noticias sobre desaparecidos

\section{Objetivos, metodología y preguntas de investigación}

De acuerdo con las estadísticas oficiales, alrededor de 14.000 personas desaparecen en España cada año. En dos de cada tres casos, entre 9.000 y 10.000 , el desaparecido es menor de edad. En torno al $99 \%$ de los expedientes se resuelven de manera exitosa en las 24 horas siguientes a la denuncia, al tratarse de casos de menores que escapan de casa y son localizados a las pocas horas. Sin embargo, el rastro de algunos niños y adolescentes sigue siendo una incógnita pese al paso del tiempo. El objetivo del estudio es analizar qué tipo de cobertura periodística han recibido estos episodios con la finalidad de identificar elementos comunes y características dominantes entre ellos.

Esta investigación se centra en el tratamiento informativo de los 15 casos de menores desaparecidos en España entre 1977 y 2015, de los que la asociación SOS Desaparecidos alerta en su web con el objetivo de lograr su localización. Se excluyen los casos de secuestro parental. De acuerdo con el registro de esta organización, los menores que continúan sin ser encontrados son: Francisco Román Fontalba (desaparecido en 1977), Juan Pedro Martínez Gómez (1986), David Guerrero (1987), Dolores e Isidro Orrit Pires (1988), Gloria Martínez (1992), Josué Monge (2006), Sara Morales (2006), Yéremi Vargas (2007), Amy FitzPatrick (2008), Ángel Carroza Altes (2012), Malén Zoe Ortiz (2013), Khrystyna Savenchuk (2014), Ricardo (2015), Sharon Santos Montero (2015) y Francisco Molina Sánchez (2015).

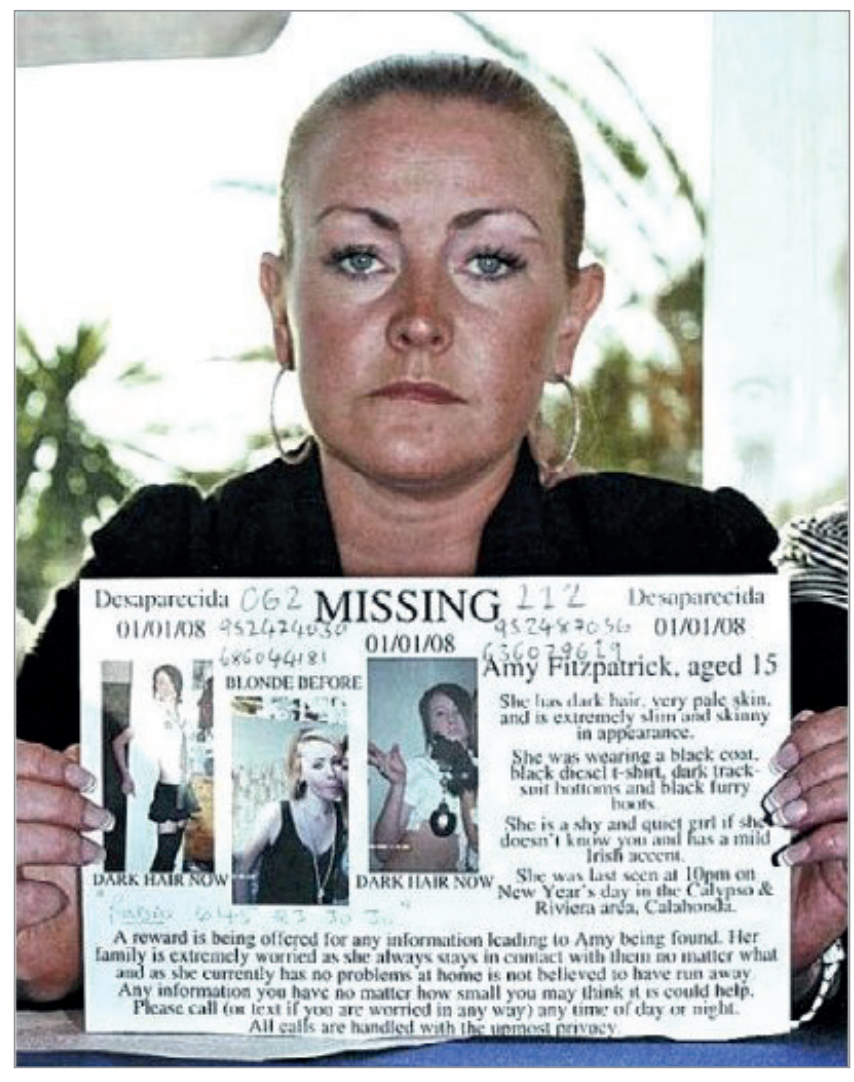

La madre de Amy Fitzpatrick muestra un cartel para su búsqueda. EFE http://elpais.com/diario/2008/01/06/sociedad/1199574004_740215.html

El estudio tiene en consideración todas las informaciones publicadas sobre estos 15 casos en los diarios españoles de difusión estatal El país, ABC, La vanguardia y El periódico durante los siete días posteriores a que se produjera la desaparición. En el caso de El periódico sólo es posible evaluar su cobertura a partir del segundo episodio dado que comenzó a editarse en 1978. Las piezas recogidas son sometidas a un análisis de contenido para responder a las siguientes preguntas de investigación:

PI1: ¿La atención mediática recibida por las 15 desapariciones analizadas es similar o existen diferencias entre ellas?

PI2: ¿Qué nivel de protección a la privacidad del menor hallamos en estas coberturas?

PI3: ¿Se detectan rasgos propios del sensacionalismo?

PI4: ¿Se observan elementos que faciliten la colaboración ciudadana?

Para contestar a estas cuestiones, las unidades de análisis han sido codificadas de acuerdo con variables consideradas significativas en este tipo de cobertura a partir de las investigaciones precedentes en este ámbito ya señaladas:

- día de publicación;

- ubicación;

- extensión;

- identificación del menor;

- inclusión de imágenes;

- fuentes de información citadas;

- retórica del miedo;

- especulaciones; 
Tabla 1. Seguimiento de los casos analizados

\begin{tabular}{|l|c|c|}
\hline \multicolumn{1}{|c|}{ Medio } & Piezas publicadas & Casos \\
\hline La vanguardia & 2 & 2 \\
\hline El periódico & 4 & 3 \\
\hline ABC & 11 & 4 \\
\hline Elpaís & 11 & 3 \\
\hline
\end{tabular}

- conexión con otros casos;

- vías de contacto para la ciudadanía.

\section{Resultados}

La revisión de los ejemplares publicados durante los siete días posteriores al momento de la desaparición permite observar que sólo 6 de los 15 episodios (40\%) tomados como objeto de estudio recibieron cobertura por parte de los diarios examinados. Los menores sobre los que se ha hallado información y el número de publicaciones que generaron, son:

- Juan Pedro Martínez Gómez, "niño de Somosierra": 9

- David Guerrero, "niño pintor" de Málaga: 2

- hermanos Orrit Pires: 1

- Josué Monge: 1

- Yéremi Vargas: 9

- Amy FitzPatrick: 6.

Como puede observarse, 24 de las 28 noticias recabadas se agrupan en tres de los seis episodios sobre los que se generó cobertura informativa, el primero de ellos y los dos más recientes. Asimismo, resulta significativo que los seis casos que recibieron atención periodística en los medios analizados delimiten dos intervalos de tiempo: los tres primeros se desarrollaron entre 1986-1988, mientras que los tres últimos tuvieron lugar en el período 2006-2008, lo que permite sugerir que la concentración temporal de las desapariciones favorece su seguimiento informativo.

En relación con los diarios analizados, las dos cabeceras que se editan desde Madrid, El país y ABC, concentraron el $80 \%$ de las unidades de análisis recogidas. No obstante, este dato no permite afirmar que ambas publicaciones informaran sobre más casos que los diarios de edición catalana, La vanguardia y El periódico, sino que dieron un mayor seguimiento a las desapariciones de las que se hicieron eco.

El examen de las piezas permite observar cuál es la evolución del seguimiento a lo largo de los siete días analizados. No se encuentra ninguna información publicada el día posterior a la desaparición, pese a que las 24 horas siguientes a la pérdida del rastro de un menor parecen esenciales para la investigación, tal y como reconocen los sistemas de alerta temprana activados por la Administración. La cobertura se inicia a partir de la segunda jornada, aunque es el quinto día posterior a la desaparición el que concentra un mayor número de informaciones (25\%), un dato que podría relacionarse con la necesidad de las familias de dirigirse a cauces diferentes a los institucionales ante la no resolución del caso.

Si se atiende a la ubicación de las informacio-

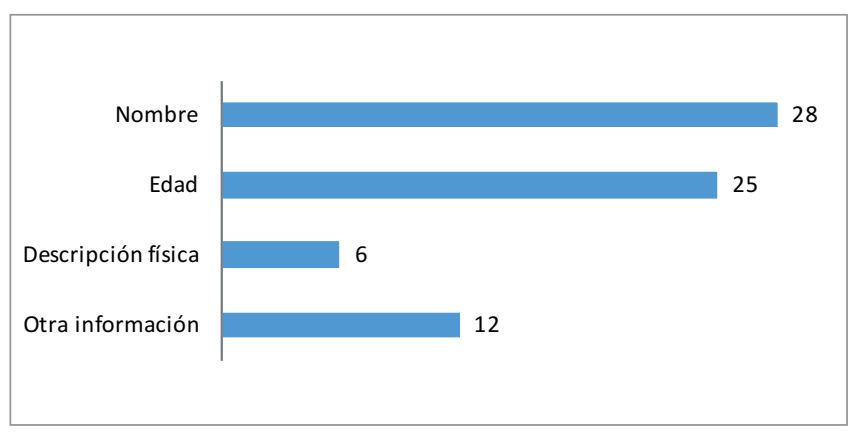

Figura 1. Noticias con elementos de identificación del menor

nes examinadas, la mayoría de las piezas ocupan emplazamientos privilegiados: el $86 \%$ se sitúa en la mitad superior de la página. No obstante, las informaciones se incluyen prácticamente de manera indistinta en página par (54\%) e impar (46\%). La jerarquización es especialmente relevante en los dos episodios más recientes:

- 2 de cada 3 piezas relacionadas con el caso de Yéremi Vargas (2007) fueron situadas en la mitad superior de una página impar;

- la cobertura del episodio de Amy FitzPatrick (2008) fue la única que motivó una información en la contraportada del diario $A B C$.

En relación con la extensión, prevalece la de tamaño medio, pues se identifica un predominio de piezas que ocupan entre una o dos columnas (36\%) o que superan la media página (32\%).

Como puede observarse en la figura 1, la identificación de los menores desaparecidos se correspondió, en la mayoría de las ocasiones, con la publicación del nombre del niño/a ( $100 \%$ de las piezas) y su edad (89\%). Mucho menos habitual fue la inclusión de la descripción física del desaparecido (25\%), pese a que ello pudiera contribuir a su reconocimiento por parte de los ciudadanos, o la difusión de otros datos, como los relativos a su carácter. En esta misma línea, cabe señalar que la mayor parte de las piezas analizadas (61\%) no incluyeron ninguna imagen. Sólo ocho informaciones (31\%) incorporaban una fotografía del menor que se buscaba.

La figura 2 muestra que, como se ha observado en estudios previos, las fuentes policiales tienen un peso fundamental en la construcción de estas coberturas informativas, pues se citan en el $71 \%$ de las piezas analizadas. No obstante, las voces más habituales son las de los familiares del niño desa-

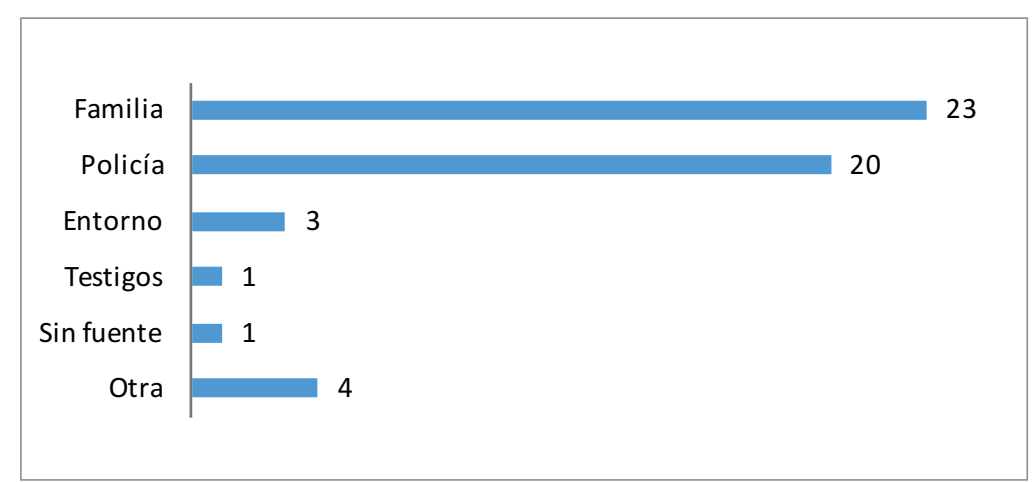

Figura 2. Fuentes de información utilizadas en las informaciones analizadas 
parecido (82\%). La acción de la familia durante las jornadas posteriores a la pérdida del menor se revela como un factor motivador de la cobertura informativa. Muchas de las noticias observadas son resultado de esas iniciativas:

- "Llamamiento de los familiares del niño desaparecido en el accidente de Somosierra" (ABC, 29/06/1986);

- "[...] Milagros Suárez, tía materna del pequeño, se ha convertido en la única portavoz de la familia" (El periódico, 15/03/2007);

- "[...] aseguró ayer su prima Nicola en una conferencia de prensa sin preguntas" (El país, 06/01/2008).

Otras fuentes, del entorno del menor o testigos, tienen un peso mucho menor.

El relato sensacionalista de las desapariciones de menores se fundamenta en el tratamiento dramático del caso y en el uso de imágenes para facilitar la identificación de la audiencia con los protagonistas

El enmarcado sensacionalista de la información se puede observar a partir de tres elementos:

En primer lugar, el empleo de la retórica del miedo y del suspense, de enorme atractivo cuando queda ligada al poder simbólico de la infancia, aparece presente en el $50 \%$ de las unidades examinadas:

- "Misterio sobre la desaparición de un niño en el accidente de Somosierra" (ABC, 28/06/1986);

"Misteriosa desaparición en Málaga del 'niño pintor"” (ABC, 10/04/1987);

\section{El caso del niño de Somosierra: la desaparición más extraña de Europa}

》 En junio de 1986, Juan Pedro Martinez Gómez y sus padres sufrieron un accident en que viajaban. El matrimonio murió en el acto, pero el cuerpo del menor, de 10

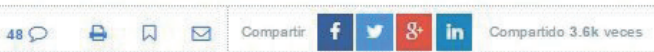

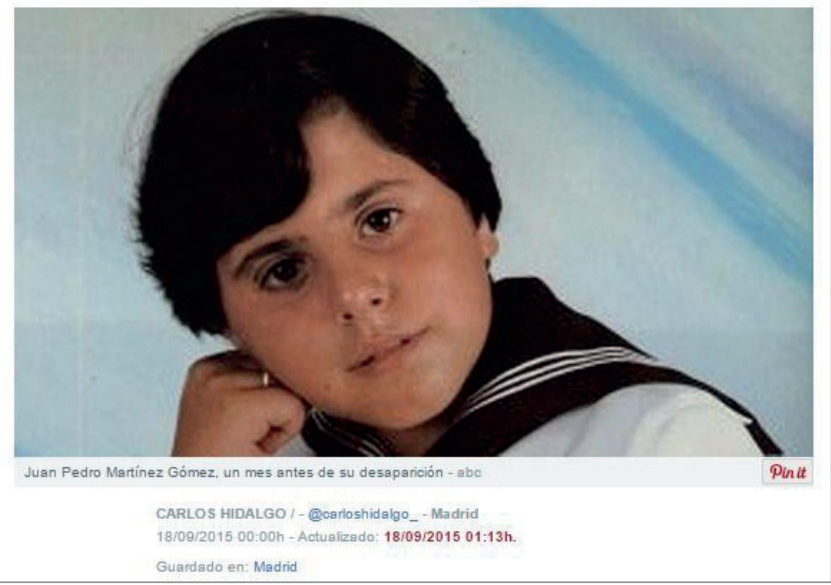

Información recordatorio

http://www.abc.es/madrid/20150918/abci-nino-camion-somosierracaso-201509171948.html

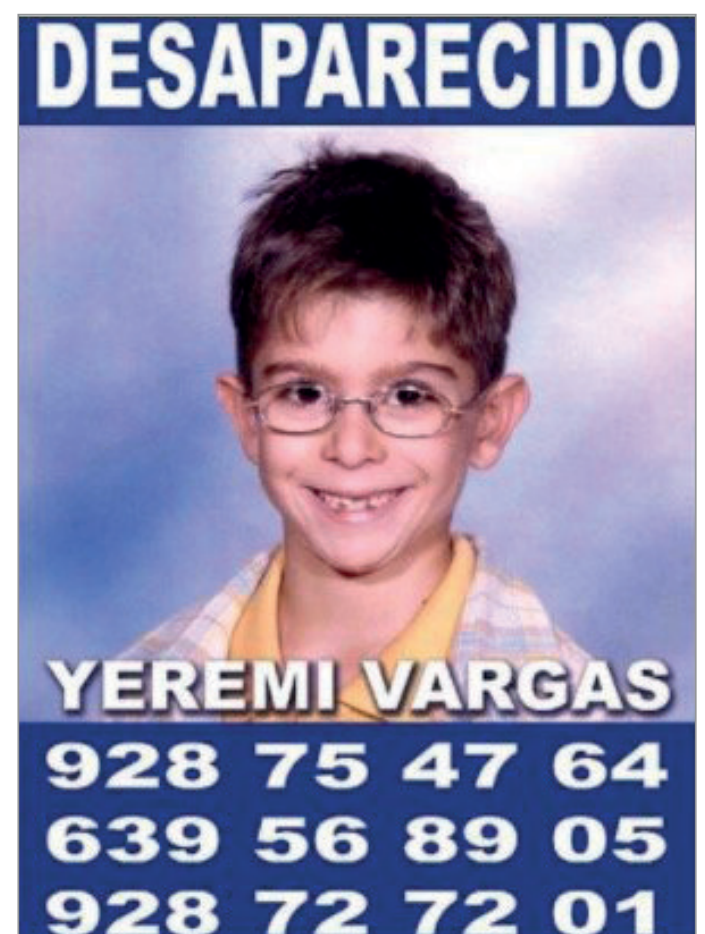

Foto difundida para localizar al niño Yéremi Vargas, desaparecido de su domicilio de Vecindario, Gran Canaria. EFE

http://elpais.com/elpais/2007/03/17/actualidad/1174123020 850215. html

- "Cada minuto, hora y día que pasan aumenta la angustia y la desesperación en la isla de Gran Canaria, que desde el sábado pasado vive conmocionada" (El periódico, 15/03/2007);

- "La desaparición en Mijas [...] reabre la memoria del siniestro triángulo de la Costa del Sol" (ABC, 06/01/2008);

- "Temor por la desaparición de una chica irlandesa de 15 años que vivía en Mijas" (La vanguardia, 06/01/2008).

El tratamiento sensacionalista puede evidenciarse también con la inclusión de informaciones no verificadas que dotan de mayor atractivo a la noticia. Estas especulaciones se han observado en un elevado número de las piezas codificadas (82\%):

- "Los familiares no descartan incluso que el muchacho haya sido recogido por algún vehículo en las horas siguientes al accidente y haya cruzado la frontera" (ABC, 29/06/1986);

- "La investigación de los familiares descarta un secuestro y baraja la hipótesis de una huida intencionada por las malas notas escolares" (El periódico, 17/04/2006);

- "Los investigadores [...] no descartan ninguna hipótesis, incluido que alguno de sus familiares más cercanos pueda estar relacionado con este suceso" (El país, 15/03/2007);

- "Un hombre había invitado a la joven de Mijas a subir a un coche, según una amiga" ( $A B C, 08 / 01 / 2008)$.

Por último, resulta revelador del enfoque sensacionalista establecer conexiones entre el caso que es noticia y otros previos, pese a no existir evidencia alguna de que estén relacionados. Es un elemento identificable en el $25 \%$ de las piezas:

- "Los vecinos y familiares temen que se reproduzca el caso de Sara Morales [...] de la que aún no se sabe nada" (EI país, 13/03/2007); 
- " [...] del segundo caso de desaparición en la isla en catorce meses, ya que la joven de 15 años Sandra Morales sigue sin dar señales de vida" (ABC, 14/03/2007);

- "El recuerdo de los casos de Rocío Wanninkhof y Sonia Carabantes, ocurrido en esa misma zona, hizo correr el miedo" (La vanguardia, 06/01/2008).

La búsqueda de elementos que faciliten la colaboración ciudadana para aportar pistas que pudiesen contribuir a la resolución del caso muestra que sólo tres de las informaciones incorporaron este tipo de recursos. En ellas, vinculadas con las desapariciones más recientes (Amy Fitzpatrick y Yéremi Vargas), se difunden los números de teléfono a los que aquellos con un testimonio relevante deben llamar.

\section{Conclusiones}

Los resultados de la investigación demuestran que la desaparición de un menor no siempre es noticia en España. Sólo una minoría de los episodios analizados recibió cobertura, aunque la mayoría de estas informaciones fueron privilegiadas en cuanto a su jerarquización en el espacio del periódico y ocuparon una extensión que podemos valorar como media.

Domina el tratamiento sensacionalista, la retórica del miedo, la publicación de conjeturas y la relación de un determinado caso con otros previos sin fundamento alguno

Tres circunstancias podrían motivar el tratamiento informativo:

- elementos especialmente misteriosos ligados a la desaparición;

- concurrencia temporalmente próxima de otros episodios;

- iniciativa de las familias en busca de atención mediática.

Como el análisis ha evidenciado, la atención de los medios ha sido más intensa en aquellos episodios en los que se conocen acciones emprendidas por familiares, a través de:

- Ilamamientos públicos y comunicados (Juan Pedro Martínez Gómez y Amy FitzPatrick);

- nombramiento de portavoces para relaciones con los periodistas y convocatoria de concentraciones para sumar apoyo vecinal (Yéremi Vargas);

- realización de ruedas de prensa y distribución de fotografías del desaparecido (Amy FitzPatrick).

Futuras investigaciones deberán ahondar en esta correlación. Por otro lado, los dos casos con mayor cobertura son de dos menores varones, lo que impide confirmar que estos diarios hayan seguido la rutina de aumentar el seguimiento cuando la desaparición afecta al sexo femenino, como apuntan estudios previos.

La privacidad de los menores es respetada parcialmente. Pese a que su identificación es completa, son minoría los casos en los que la noticia se acompaña de imágenes del desaparecido. Estas son más habituales en las coberturas más recientes.

El enmarcado sensacionalista es fruto de diferentes estrategias, aunque predomina la construcción de la noticia desde una retórica del miedo y la inclusión de hipótesis sin confirmar. La presencia de este enfoque en todos los diarios analizados confirma que el sensacionalismo ha logrado abrirse paso entre la prensa pretendidamente seria.

La cooperación de los medios con la investigación no se concreta más que en contadas ocasiones, en las que se facilitan teléfonos para la colaboración ciudadana. El interés humano de las historias se privilegia frente al servicio público por el que debe velar el periodismo.

Futuros trabajos deberán profundizar en estas tendencias a través de estudios que puedan contrastar diacrónicamente la cobertura entre distintos tipos de medios y proponer orientaciones deontológicas específicas para este tipo de coberturas.

\section{La cooperación de los medios y la policía} es necesaria dado el carácter simbiótico de su relación

\section{Agradecimientos}

Este trabajo se inscribe en el Proyecto $1+D+i$, código CSO2015-66667-R, Cambios en la empresa periodística: la estrategia del sensacionalismo. Su emergencia histórica en España y América, financiado por el Ministerio de Economía y Competitividad de España.

\section{Bibliografía}

Alexander, Yonah (1978). "Terrorism, the media and the police". Journal of international affairs, v. 32, n. 1, pp. 101-113. https://www.jstor.org/stable/24356774 
Altheide, David L. (2002). "Children and the discourse of fear". Symbolic interaction, v. 25, n. 2, pp. 229-250. https://doi.org/10.1525/si.2002.25.2.229

Altheide, David L. (2003). "Mass media, crime, and the discourse of fear". The hedgehog review, v. 5, n. 3, pp. 9-25. http://www.iasc-culture.org/THR/archives/Fear/5.3CAltheide. $p d f$

Barrios-Vallejo, Carlota (2016). Guía Odiseo para familiares de desaparecidos en los medios de comunicación. Asociación SOS Desaparecidos.

http://sosdesaparecidos.es/guia-odiseo

BBC (2010). Editorial guidelines: privacy and missing people. http://www.bbc.co.uk/editorialguidelines/guidance/missingpeople

Belda-García, Luis-Miguel; Maíllo-Belda, Juan-Emilio; Prieto-Ampudia, José-María (2008). Periodismo social. El compromiso de la información. Libro de estilo. Servimedia.

http://www.servimedia.es/LibroEstilo.pdf

Best, Joel (1987). "Rhetoric in claims-making: Constructing the missing children problem". Social problem, v. 34, n. 2, pp. 101-121.

https://goo.gl/f8B2yo

https://doi.org/10.2307/800710

Brookman, Fiona (2005). Understanding homicide. London: SAGE. ISBN: 9780761947554

Bucqueroux, Bonnie; Seymour, Anne (2009). A guide for journalists who report on crime and crime victims. Justice solutions.

http://www.mediacrimevictimguide.com/journalistguide. $p d f$

Conlin, Lindsey; Davie, William R. (2015). “Missing white woman syndrome: How media framing affects viewer's emotions". Electronic news, v. 9, n. 1, pp. 36-50.

https://doi.org/10.1177/1931243115572822

Critcher, Chas (2002). "Media, government and moral panic: The politics of paedophilia in Britain 2000-1". Journalism studies, v. 3, n. 4, pp. 521-535.

https://goo.gl/ncgOjH

https://doi.org/10.1080/1461670022000019182

Critcher, Chas (2008). "Moral panic analysis: Past, present and future". Sociology compass, v. 2, n. 4, pp. 1127-1144. http://www.penelopeironstone.com/Critcher.pdf https://doi.org/10.1111/j.1751-9020.2008.00122.x

Diezhandino-Nieto, María-Pilar (1993). "El 'periodismo de servicio', la utilidad en el discurso periodístico". Anàlisi, v. 15, pp. 117-125.

http://www.raco.cat/index.php/Analisi/article/view/41192/89145

El país (1996). Manual de estilo del diario El país. http://blogs.elpais.com/files/manual-de-estilo-de-elpa\%C3\%ADs.pdf

Findlay, Preston; Lowery, Robert G. (2011). Menores desaparecidos y sustraídos: guía policial para investigación de casos y manejo de programas. National Center for Missing \& Exploited Children.
http://www.missingkids.org/en_US/publications/NC32.pdf

Fritz, Noah J.; Altheide, David L. (1987). "The mass media and the social construction of the missing children problem". The sociological quarterly, v. 28, n. 4, pp. 473-492. https://doi.org/10.1111/j.1533-8525.1987.tb00307.x

Gans, Herbert J. (1979). Deciding what's news: A study of CBS evening news, NBC nightly news, Newsweek, and Time. Evanston: Northwestern University Press. ISBN: 978 0094633902

Gladis, Stephen D. (1979). "The hostage/terrorist situation and the media". FBI law enforcement bulletin, v. 48, n. 9, pp. 11-15.

https://www.ncjrs.gov/pdffiles1/Digitization/61628NCJRS. $p d f$

Glassner, Barry (1999). The culture of fear: Why Americans are afraid of the wrong things. New York: Basic Books. ISBN: 9780465003365

Goode, Erich; Ben-Yehuda, Nachman (1994). Moral panics: The social construction of deviance. Oxford: Blackwell. ISBN: 9781405189347

Greer, Chris; McLaughlin, Eugene (2012). "Media justice: Madeleine McCann, intermediatization and 'trial by media' in the British press". Theoretical criminology, v. 16, n. 4, pp. 395-416. https://doi.org/10.1177/1362480612454559

Griffin, Timothy; Miller, Monica K. (2008). "Child abduction, Amber alert, and crime control theater". Criminal justice review, v. 33, n. 2, pp. 159-176.

https://doi.org/10.1177/0734016808316778

Griffin, Timothy; Miller, Monica K.; Hoppe, Jeffrey; Rebideaux, Amy; Hammack, Rachel (2007). "A preliminary examination of Amber alert's effects". Criminal justice policy review, v. 18, n. 4, pp. 378-394.

https://doi.org/10.1177/0887403407302332

Guffey, James E. (1992). "The police and the media: Proposals for managing conflict productively". American journal of police, v. 11, n. 1, pp. 33-51.

http://heinonline.org/HOL/LandingPage?handle=hein. journals/ajpol11\&div=7\&id=\&page=

Herbert, John (2000). Journalism in the digital age: Theory and practice for broadcast, print and online media. London: Routledge. ISBN: 9780240515892

Innes, Martin (1999). "The media as an investigative resource in murder enquiries". The British journal of criminology, v. 39, n. 2, pp. 269-286.

https://goo.gl/eQzSyY

https://doi.org/10.1093/bjc/39.2.269

Johnson-Cartee, Karen S. (2005). News narratives and news framing: Constructing political reality. Lanham: Rowman \& Littlefield Publishers. ISBN: 9780742536630

Kitzinger, Jenny; Skidmore, Paula (1995). "Playing safe: Media coverage of child sexual abuse prevention strategies". Child abuse review, v. 4, pp. 47-56.

https://doi.org/10.1002/car.2380040108

Lazarsfeld, Paul; Merton, Robert (1985). “Comunicación de 
masas, gustos populares y acción social organizada”. En: DeMoragas-Spà, Miquel. Sociología de la comunicación de masas II: estructura, funciones y efectos. Barcelona: Gustavo Gili, pp. 22-49. ISBN: 9688872415

Liebler, Carol M. (2010). "Me(di)a culpa?: The 'Missing white woman syndrome' and media self-critique". Communication, culture \& critique, v. 3, n. 4, pp. 549-565.

https://goo.gl/uqn33s

https://doi.org/10.1111/j.1753-9137.2010.01085.x

Luzón, Virginia; Ferrer, Iliana (2008). “Espectáculo informativo en noticias de sociedad: el caso de Madeleine McCann". Trípodos, n. 22, pp. 137-148.

http://www.raco.cat/index.php/tripodos/article/ viewFile/76531/97284

Missing People (2011). Working with the media. Missing People Guidance.

https://goo.gl/SIg6iR

Moeller, Susan D. (2002). "A hierarchy of innocence. The media's use of children in the telling of international news". The international journal of press/politics, v. 7, n. 1, pp. 36-56. https://doi.org/10.1177/1081180X0200700104

MPAN (2016). Missing persons guide: media attention. Missing Persons Advocacy Network.

http://www.missingpersonsguide.com/media

NPIA (2010). Guidance on the management, recording and investigation of missing persons. National Policing Improvement Agency.

http://ec.europa.eu/justice/fundamental-rights/files/ missing_persons_sec_edn_2010_en.pdf

Redondo-García, Marta (2013). “El sensacionalismo y su penetración en la prensa española de calidad. El "caso McCann" en El país, El mundo y $A B C$ ". Estudios sobre el mensaje periodístico, v. 19, n. 1, pp. 235-253.

https://doi.org/10.5209/rev_ESMP.2013.v19.n1.42519

RTVE (2010). "La intimidad de las víctimas". Manual de estilo de RTVE. Directrices para los profesionales. Radio Televisión Española.

https://goo.gl/qYM5Mr

Rudin, Richard; Ibbotson, Trevor (2003). Introduction to journalism: Essential techniques and background knowl- edge. Burlington: Focal Press. ISBN: 9780240516349

Save the Children; Unicef (2010). Infancia y medios de comunicación: recomendaciones para el tratamiento de la infancia en los medios de comunicación. Valencia: Unicef. https://www.savethechildren.es/sites/default/files/imce/ docs/infancia_y_medios_castellano.pdf

Schlesinger, Philip; Tumber, Howard (1993). "Fighting the war against crime. Television, police, and audience". British journal of criminology, delinquency and deviant social behaviour, v. 33, n. 1, pp. 19-32.

http://www.jstor.org/stable/23637739

Seale, Clive (2003). Media and health. London: Sage. ISBN: 9780761947301

Selke, William L.; Bartoszek, G. Marshall (1984). "Police and media relations: the seeds of conflict". Criminal justice review, v. 9, n. 2, pp. 25-30.

https://doi.org/10.1177/073401688400900204

Staller, Karen M. (2010). "Social problem construction and its impact on program and policy responses". En: Kamerman, Sheila B.; Phipps, Shelley; Ben-Arieh, Asher. From child welfare to child well-being: An international perspective on knowledge in the service of policy making, pp. 155-173. New York: Springer. ISBN: 9789048133765

https://doi.org/10.1007/978-90-481-3377-2_10

Stillman, Sarah (2007). "'The missing white girl syndrome': Disappeared women and media activism". Gender \& development, v. 15, n. 3, pp. 491-502.

https://goo.gl/57UKV5

https://doi.org/10.1080/13552070701630665

Unió de Periodistes Valencians (2004). Pequeñas manos: manual para periodistas sobre la protección de la infancia en los medios de comunicación. Valencia: UPV.

Warren, Carl N. (1979). Géneros periodísticos informativos: nueva enciclopedia de la noticia. Barcelona: ATE. ISBN: 978 8485047512

Wilczynski, Ania; Sinclair, Kate (1999). "Moral tales: Representations of child abuse in the quality and tabloid media". Australian and New Zealand journal of criminology, v. 32, n. 3, pp. 262-283.

https://doi.org/10.1177/000486589903200305

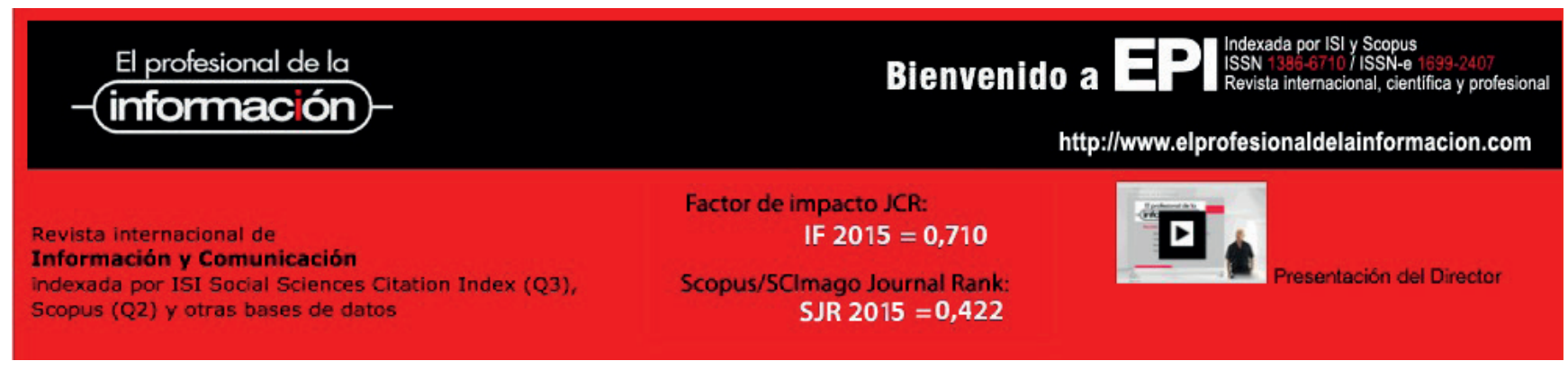


$7^{a}$ Conferencia internacional sobre revistas de ciencias sociales y humanidades

CRECS 2017

Cuenca, 4-5 mayo

Másinformación:

Isabel Olea epi.iolearogmailicom

hitpllcrecsinfo

Gestión postpublicación e impacto social y académico

مUCLM

Universidad de

Castilla La Mancha
@ANৎS

Revista de Estudios sobre Lectura

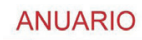 \\ Think \\ 80. SCIMAGO \\ 1 Clarivate}

ProQuest.

P.

casalinilibri 제

(3)

Fundación Dialnet UNIVERSIDAD DE LA RIOJA

\section{SPRINGER NATURE}

\section{EC3metrics}

EBSCO
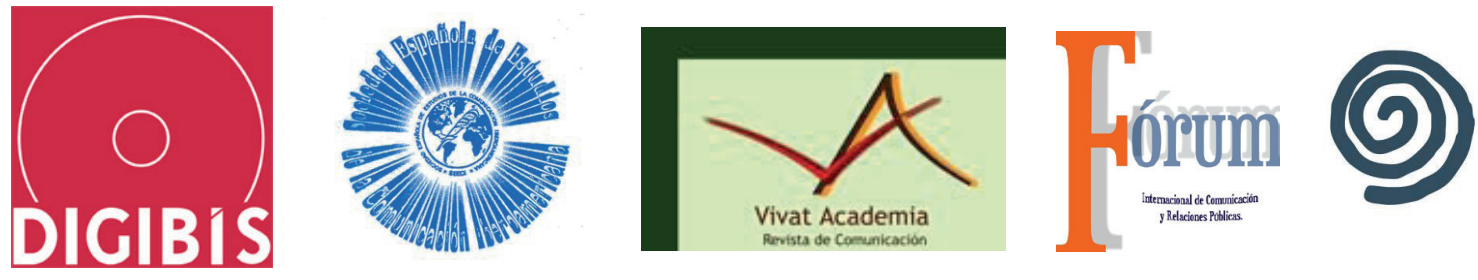

baratz 